\title{
Retrograde Bone Morphogenetic Protein Signaling Shapes a Key Circadian Pacemaker Circuit
}

\author{
E. Axel Gorostiza and M. Fernanda Ceriani \\ Laboratorio de Genética del Comportamiento, Fundación Instituto Leloir and Instituto de Investigaciones Bioquímicas-Buenos Aires (Consejo Nacional de \\ Investigaciones Científicas y Técnicas), 1405-BWE Buenos Aires, Argentina
}

The neuropeptide pigment-dispersing factor (PDF) synchronizes molecular oscillations within circadian pacemakers in the Drosophila brain. It is expressed in the small ventral lateral neurons (sLNvs) and large ventral lateral neurons, the former being indispensable for maintaining behavioral rhythmicity under free-running conditions. How PDF circuits develop the specific connectivity traits that endow such global behavioral control remains unknown. Here, we show that mature sLNv circuits require PDF signaling during early development, acting through its cognate receptor PDFR at postsynaptic targets. Yet, axonal defects by PDF knockdown are presynaptic and become apparent only after metamorphosis, highlighting a delayed response to a signal released early on. Presynaptic expression of constitutively active bone morphogenetic protein (BMP) receptors prevents $p d f r$ mutants misrouting phenotype, while sLNv-restricted downregulation of BMP signaling components phenocopied $p d f^{01}$. Thus, we have uncovered a novel mechanism that provides an early "tagging" of synaptic targets that will guide circuit refinement later in development.

\section{Introduction}

Rhythmic locomotor activity in Drosophila is sustained by a relatively complex network in the adult brain, composed of $\sim 150$ neurons grouped in seven clusters (Helfrich-Förster, 2003; Shafer et al., 2006), which need to stay in phase to maintain behavioral rhythmicity. Among circadian-relevant clusters, the small ventral lateral neurons (sLNvs) are considered essential (Renn et al., 1999b). They set the pace of most of the other oscillators in the brain (Stoleru et al., 2005) and are indispensable for sustaining behavioral rhythmicity under constant darkness (Grima et al., 2004; Stoleru et al., 2004), mediated in part by the release of the neuropeptide pigment-dispersing factor (PDF). PDF is a fundamental signal within the circadian network. Flies lacking PDF $\left(p d f^{01}\right)$ or with a defective PDF receptor (PDFR) $\left(h a n^{5304}\right)$ become largely arrhythmic in constant darkness, although some display a shorter period (Renn et al., 1999b; Hyun et al., 2005; Im et al., 2011). Furthermore, PDF commands the internal synchronization of the network in free-running conditions (Lin et al., 2004; Lear et al., 2009). Despite extensive characterization of the

\footnotetext{
Received July 18, 2012; revised 0ct. 15, 2012; accepted Nov. 11, 2012.

Author contributions: E.A.G. and M.F.C. designed research; E.A.G. performed research; E.A.G. analyzed data; E.A.G. and M.F.C. wrote the paper.

This work was supported by Agencia Nacional de Promoción Científica y Tecnológica (Argentina) Grant PICT20101874 and by Fogarty International Research Collaboration Award-NIH Grant 1R03TW008342 (M.F.C.). M.F.C. is a member of Consejo Nacional de Investigaciones Científicas y Técnicas (CONICET). E.A.G. is supported by a graduate fellowship from CONICET. We thank the Bloomington Drosophila Stock and the Vienna Drosophila RNAi Centers, as well as Orie Shafer and Paul Taghert for sharing fly stocks. We are indebted to Guillermo Lanuza for advice and to G. Lanuza, Esteban Beckwith, Nara Muraro, and Alejandro Schinder for critical reading of this manuscript.

The authors declare no competing financial interests.

Correspondence should be addressed to M. Fernanda Ceriani, Laboratorio de Genética del Comportamiento, Fundación Instituto Leloir and Instituto de Investigaciones Bioquímicas-Buenos Aires (Consejo Nacional de Investigaciones (ientíficas y Técnicas), Avenida Patricias Argentinas 435, 1405-BWE Buenos Aires, Argentina. E-mail: fceriani@leloir.org.ar.

DOI:10.1523/JNEUROSCI.3448-12.2013

Copyright $\odot 2013$ the authors $\quad 0270-6474 / 13 / 330687-10 \$ 15.00 / 0$
}

role of PDF in a circadian context, little is known about the development of the sLNvs; furthermore, the relevance of PDF in this process has never been addressed.

Synapse development has extensively been studied at the larval neuromuscular junction (NMJ) in Drosophila. The NMJ is established during embryogenesis. During larval development, muscles dramatically change their size, which is accompanied by changes in the presynaptic neurons, increasing the number of synaptic buttons and the number of active zones per button, hence maintaining synaptic efficacy (Atwood et al., 1993; Stewart et al., 1996; Zito et al., 1999). These changes require a precise coordination between presynaptic and postsynaptic partners that depends on anterograde and retrograde signals. In Drosophila, the bone morphogenetic protein (BMP) pathway acts as a retrograde signal during NMJ growth. Glass bottom boat (GBB), one of the best characterized ligands, is the retrograde cue released by the muscle. Motorneurons express the type II receptor wishful thinking (wit) and two type I receptors, saxophone (sax) and thick veins $(t k v)$ (Aberle et al., 2002; Marqués et al., 2002; Rawson et al., 2003; McCabe et al., 2004). Other classical components of the BMP pathway are involved; mothers against dpp (Mad) is phosphorylated by Tkv or Sax, dimerizes with Medea (Med) and together translocate into the nucleus, which enables it to exert its transcriptional role in the motorneuron (Rawson et al., 2003; McCabe et al., 2004).

In this work, we analyze the contribution of PDF and BMP signaling pathways, which act in concert during early development to direct the correct establishment of the PDF circuit connectivity. Employing different strategies, such as the use of null mutants and stage-specific silencing through the expression of RNAis, we demonstrate that both pathways are necessary in a subset of sLNvs for their projections to acquire their stereotypic shape and reach their target. Thus, during early development, 
PDF acts as an instructive molecule, which signals through the cognate PDF receptor to circadian and other locomotor relevant cells. Later on, at times of circuit refinement, and in response to an earlier PDF signal, postsynaptic neurons release GBB, thereby activating the canonical BMP pathway within the sLNvs.

\section{Materials and Methods}

Strains and fly rearing. Flies were reared and maintained at $25^{\circ} \mathrm{C}$ in vials containing standard cornmeal medium under $12 \mathrm{~h}$ light/dark (LD) cycles, with the exception of those including mifepristone (RU486) (Sigma-Aldrich). In those experiments, food was mixed with RU486 in $80 \%$ ethanol to a final concentration of $200 \mu \mathrm{g} / \mathrm{ml}$. $p d f-G S$ was generated in our laboratory (Depetris-Chauvin et al., 2011). pdfGAL4, tim-GAL4, UAS-Wg, UAS-CD8GFP, UAS-CD8mRFP, UAS-myrRFP, ok107-GAL4, and c232-GAL4 were obtained from the Bloomington Stock Center. pdf-GAL80 was provided by M. Rosbash (Brandeis University, Waltham, MA) (Stoleru et al., 2004). UASGBB, UAS-Tkv ${ }^{\mathrm{A}}$ (Nellen et al., 1996), UAS$\mathrm{Sax}^{\mathrm{A}}$ (Haerry et al., 1998), and UAS- $g b b^{R N A i}$ were shared by K. A. Wharton (Brown University, Providence, RI). pdf ${ }^{01}$ (Renn et al., 1999b) and $h^{5}{ }^{5304}$ (Hyun et al., 2005) were provided by O. Shafer (University of Michigan, Ann Arbor, MI) and P. Taghert (Washington University, St. Louis, MO). pdfr-GAL4 was generously provided by L. Griffith (Brandeis University, Waltham, MA) (Parisky et al., 2008). kurs58-GAL4 and mai301-GAL4 (Siegmund and Korge, 2001) were shared by G. Korge (Freie Univerität Berlin, Berlin, Germany). UAS- $p d f^{R N A i-4380 G D}$, UAS- $p d f r^{R N A i-42724 G D}$, UAS- $t k v^{R N A i-105834 k k}$, UAS-wit ${ }^{R N A i-103808 K K}$, UAS-med ${ }^{\text {RNAi-106767KK', }}$ UAS-EcR ${ }^{R N A i-37059 G D}$, and UAS-Dicer2 were obtained from Vienna Drosophila RNAi Center (transformant ID numbers 4380, 42724, 105834, 103808, 106767, and 37059, and stock number 60008, respectively). UAS- $t k v^{R N A i-31040 T r i p}$, UAS-wit ${ }^{R N A i-25949 T r i p}$, UAS$m e d^{R N A i-31928 T r i p}$, UAS- $d p p^{R N A i-33767 T r i p}$, UAS$m y o^{R N A i-31114 T \text { Trip }}, \mathrm{UAS}-\mathrm{mav}^{R N A i-34650 T \text { Trip }}$, and UAS-act ${ }^{R N A i-29597 T r i p}$ were obtained from the Bloomington Stock Center.

Dissection and immunofluorescence. For adult brain immunohistochemistry, 7- to 10$\mathrm{d}$-old flies were employed. Adult heads were fixed with $4 \%$ formaldehyde in $100 \mathrm{~mm}$ phosphate buffer $\mathrm{pH} 7.5$ for $45 \mathrm{~min}$ at room temperature (RT). Brains were dissected and rinsed three times in PBS with $0.1 \%$ Triton $\mathrm{X}-100$ (PT) for $15 \mathrm{~min}$. Samples were blocked in $7 \%$ normal goat serum for $1 \mathrm{~h}$ in $\mathrm{PT}$ and incubated with primary antibody at $4^{\circ} \mathrm{C}$ overnight. The primary antibodies employed were rabbit anti-GFP (1:500; Invitrogen), rabbit anti-RFP (1:500; Rockland), and homemade rat anti-Drosophila-PDF (1:500) (Depetris-Chauvin et al., 2011). Samples were washed four times for 15 min each time in PT and incubated with secondary antibody at 1:250 for $2 \mathrm{~h}$ at RT, and secondary antibodies were washed four times for 15 min each time in PT and mounted in $80 \%$ glycerol in PT. The second-

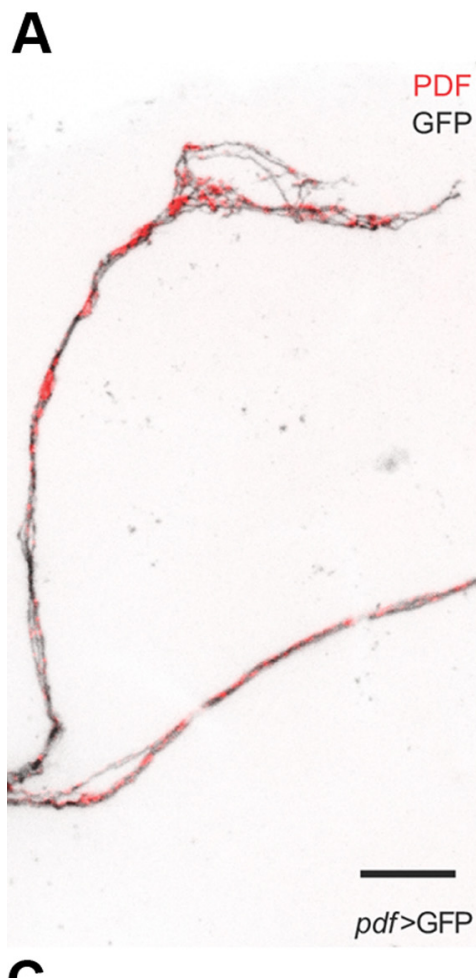

B
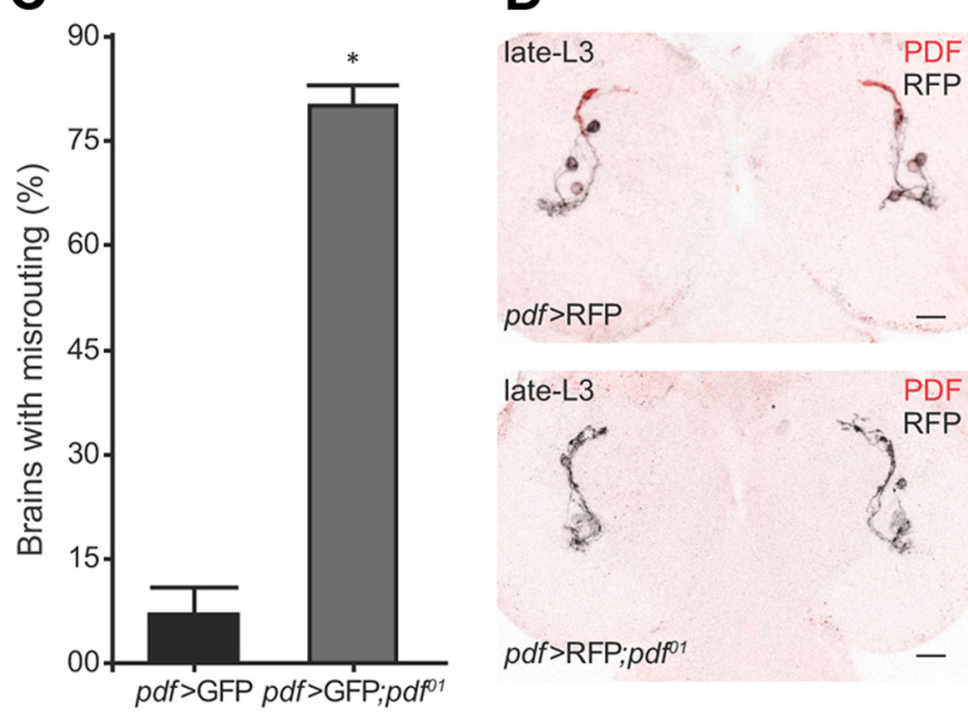

Figure 1. A subset of the sLNv projections displays an aberrant morphology in $p d f^{01} . A, B$, Representative confocal images of the $s L$ Nv dorsal projections in control $\left(p d f>G F P ; A\right.$ ) and mutant $\left(p d f>G F P ; p d f^{01} ; \boldsymbol{B}\right)$ brains. A subset of the sLNvs projections (black arrow) continues growing toward the posterior optic tract (POT). Brains were stained with anti-GFP (shown in black) and anti-PDF (shown in red) antibodies. The average length of the abnormal axons was $106.7 \mu \mathrm{m}$ with a SD of $33.5 \mu \mathrm{m}$. C, Quantitation of the misrouting phenotype. The percentage of brains displaying aberrant fibers was significantly different between $p d f>$ GFP and $p d f>$ GFP; $p d f^{01}$ (one-way ANOVA, $p<0.001$ ). Approximately $80 \%$ of the mutant brains show a misrouting defect in contrast to $7 \%$ in controls. Similar results were obtained employing different markers. Although quantitation was performed on a single brain hemisphere, the defect is largely present in both. Experiments were repeated three times independently. In each experiment, 10 flies were analyzed per genotype, and a mean value was obtained. Error bars indicate SEM. The asterisk indicates a significant difference between genotypes. $\boldsymbol{D}$, Representative confocal images of sLNvs dorsal projections from late third-instar larvae from $p d f>$ RFP (top panel) and $p d f>$ RFP; $p d f^{p 1}$ (bottom panel). No differences were detected. The defect was only present in a small proportion of the brains ( $p d f>R F P, 8 \% ; p d f>R F P ; p d f^{01}, 0 \%$; Kruskal-Wallis, $p=0.40$ ). Scale bars: $A, B, D, 20 \mu \mathrm{m}$.

ary antibodies used were Cy2- and Cy3-conjugated anti-rabbit, and Cy5and Cy3-conjugated anti-rat (Jackson ImmunoResearch). Images were taken either on a Zeiss Pascal LSM or a Zeiss LSM 510 Meta confocal microscope. After acquisition, images were processed employing Fiji, an ImageJ-based image-processing environment (downloaded from http://fiji.sc/Fiji). 
A

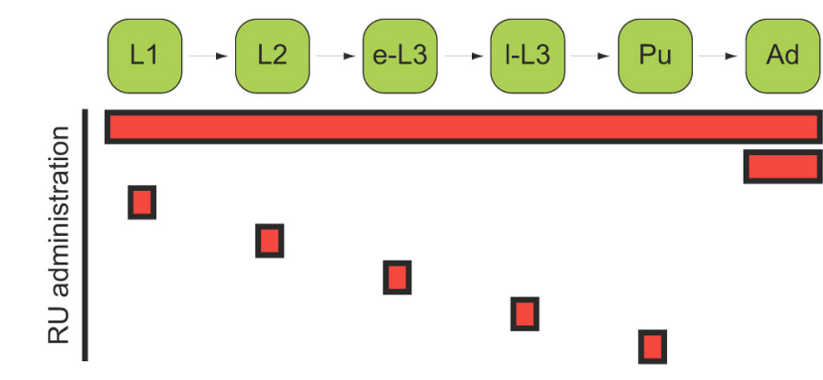

C

\begin{tabular}{|c|c|c|c|}
\hline Stage & Genotype & $\%$ of defect & $p$-value \\
\hline Dev+Ad & $\begin{array}{c}p d f-G S>+ \\
p d f-G S>p d f \text { RNAi }\end{array}$ & $\begin{array}{l}24.5 \\
75.9\end{array}$ & $<0.001$ \\
\hline Ad & $\begin{array}{c}p d f-G S>+ \\
p d f-G S>p d f \text { fNAi }\end{array}$ & $\begin{array}{l}6.7 \\
3.3\end{array}$ & 0.590 \\
\hline L1 & $\begin{array}{c}p d f-G S>+ \\
p d f-G S>p d f^{R N A i}\end{array}$ & $\begin{array}{c}3.7 \\
66.0 \\
\end{array}$ & $<0.001$ \\
\hline L2 & $\begin{array}{c}p d f-G S>+ \\
p d f-G S>p d f^{R N A i}\end{array}$ & $\begin{array}{l}10.4 \\
17.9\end{array}$ & 0.230 \\
\hline early-L3 & $\begin{array}{c}p d f-G S>+ \\
p d f-G S>p d f^{R N A i}\end{array}$ & $\begin{array}{c}3.7 \\
13.3\end{array}$ & 0.126 \\
\hline late-L3 & $\begin{array}{c}p d f-G S>+ \\
p d f-G S>p d f^{R N A i}\end{array}$ & $\begin{array}{l}3.3 \\
0.0 \\
\end{array}$ & 0.590 \\
\hline Pupa & $\begin{array}{c}p d f-G S>+ \\
p d f-G S>p d f^{R N A i}\end{array}$ & $\begin{array}{c}3.3 \\
10.0\end{array}$ & 0.284 \\
\hline
\end{tabular}

B

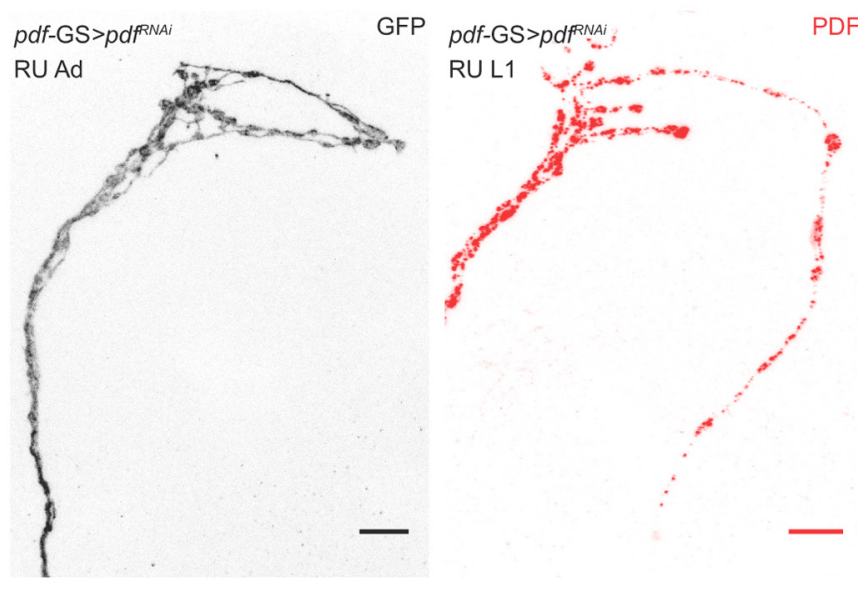

D

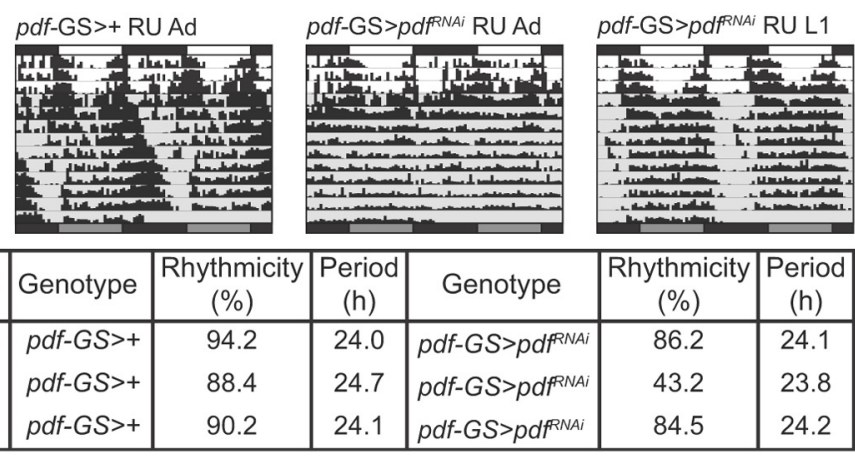

Figure 2. PDF is required early on during circuit establishment. $A$, Outline of the specific treatments. Control ( $p d f-G S>+$ ) and $p d f^{R N A i-43806 D}$ ( $p d f-G S>p d f^{R N A i-43806 D}$ ) flies were employed. Six stages were selected to evaluate PDF requirement. Activation of $p d f^{P N A i-43806 D}$ expression during larval stages was accomplished after a 2 min dip in RU486. Delivering RU486 to pupae required a small anterior incision in the pupal case. For acute activation of $p d f^{P N A i-4380 G D}$ in the adult, flies were transferred to standard vials supplemented with RU486. To mimic $p d f^{p 1}$ conditions, $p d f-G S>p d f^{\beta N A i-4380 G D}$ flies were raised throughout development in food supplemented with RU486. B, C, PDF is required in L1. B, Representative confocal images of the projections from $p d f-G S>p d f^{\text {PNAi-4380GD }}$ adult brains treated with RU486 during adulthood (left) or L1 (right). Brains were stained with anti-GFP (black) and anti-PDF (red) antibodies. PDF downregulation during adulthood did not trigger any misrouting defect. Scale bar, $10 \mu \mathrm{m}$. C, Summary of the results obtained. Statistical analysis included a two-way ANOVA. The interaction was significant ( $p<0.001)$. Only treatments involving downregulation in L1 reproduced the sLNv aberrant morphology. Interestingly, downregulation of PDF levels in I-L3 and pupal stages gave rise to abnormal large LNvs. Experiments were repeated three times independently; 10 brains were analyzed per genotype/experiment; the mean value is reported. $\boldsymbol{D}$, The misrouting phenotype does not affect locomotor behavior. Representative actograms of selected genotypes are shown. PDF downregulation in L1 does not affect period or rhythmicity; adult-specific PDF silencing phenocopied the locomotor defects observed in $p d f^{01}$. Note that RU486 administration extends the free-running period during administration. Period analysis included a one-way ANOVA $(p=0.0001)$ with Tukey's post hoc test ( $p<0.05$; least-significant difference, $0.44 \mathrm{~h}$ ). Rhythmicity analysis included a one-way ANOVA ( $p<0.0001$, Tukey, $p<0.05$; least-significant difference, 17.27\%). Experiments were independently repeated three times, with $\sim 32$ flies analyzed per genotype/experiment.

For $p d f^{R N A i-4380 G D}$ and $m e d^{R N A i-106767 K K}$ (in Fig. 5) experiments, females were allowed to lay eggs on yeasted agar plates for $5 \mathrm{~h}$ at $25^{\circ} \mathrm{C}$ to have animals of accurately defined stages. For acute stimulation, different larval stages were washed with water and transferred to $1 \mathrm{ml}$ of RU486 (4 $\mu \mathrm{g} / \mu \mathrm{l})$ in a sample tube, where they resided for $2 \mathrm{~min}$. To deliver RU486 to pupae, we used pupae collected $7 \mathrm{~d}$ after egg laying and performed an anterior small incision in the pupal case before the immersion in RU486. In both cases, after RU486 immersion, larva or pupae were gently placed in a new vial containing standard food. Adult induction was performed transferring newly eclosed flies into vials containing standard cornmeal medium supplemented with RU486. In all cases, adult brain dissections were performed $10 \mathrm{~d}$ after adult emergence.

For 1-L3 brain immunohistochemistry, larvae were dissected in PBS and brains were fixed with $4 \%$ formaldehyde in $100 \mathrm{~mm}$ phosphate buf-

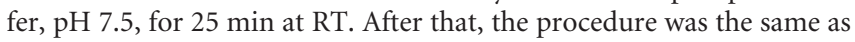
described above for adult brains.

Axonal length. The Fiji software was used to measure the length of the aberrant axonal projections. The starting point was decided to be the one where the projection(s) taking the aberrant path crosses the most ventral neurite (indicated by an asterisk in Fig. 1). An axonal length of $>20 \mu \mathrm{m}$ was considered abnormal. The length of the sLNvs dorsal arborization was also measured. The starting point was set at the lateral horn and the maximal length was measured toward the midbrain. Lengths of $<36.40$ $\mu \mathrm{m}$ (corresponding to 4 SDs shorter than that of controls) were considered aberrant.

Locomotor behavior analysis. Flies were entrained to $12 \mathrm{~h} \mathrm{LD}$ cycles during their entire development. L1 induction was performed as previously described. Newly eclosed adult males were placed in glass tubes containing standard food or standard food supplemented with 200 $\mu \mathrm{g} / \mathrm{ml}$ RU486 and monitored for activity with infrared detectors and a computerized data collection system (TriKinetics). Activity was monitored in LD conditions for 3-4 d, followed by constant darkness for at least a week (DD1-8). Period and rhythmicity were estimated using ClockLab software (Actimetrics). Flies with a single peak over the significance line $(p<0.05)$ in a $\chi^{2}$ analysis were scored as rhythmic, which was confirmed by visual inspection of the actograms. Flies classified as weakly rhythmic (Ceriani et al., 2002) were not taken into account for average period calculations.

Statistical analysis. Statistical analyses were performed with InfoStat, version 2009 (Grupo InfoStat, Facultad de Ciencias Agropecuarias, Universidad Nacional de Córdoba, Córdoba, Argentina). Whenever possible ANOVA was performed. Otherwise, the nonparametric Kruskal-Wallis test was used. Normality was tested using Shapiro-Wilks test, and the homogeneity of variance was assessed with Levene's test. A value of $p<$ 
0.05 was considered statistically significant. After ANOVA, a Tukey least-significant difference test was performed. When in a two-way ANOVA, an interaction between factors was significant, simple effects were performed, and $p$ values were informed.

\section{Results}

Loss of PDF correlates with misrouting of the adult sLNv projections

To investigate a possible requirement of the PDF neuropeptide in the establishment of the LNv circuitry, we examined its adult morphology in a $p d f^{01}$ null background. Transgenic $p d f$-gal4;UAS-mCD8GFP or mCD8RFP flies (from here on referred to as $p d f>\mathrm{GFP} / \mathrm{RFP}$ ) were examined in wild-type and mutant backgrounds. CD8 reporters recreated the entire PDF circuit, namely the small and large LNv somatas as well as their axonal and dendritic projections.

The sLNvs send their axonal projections toward the dorsal protocerebrum, where they arborize in a highly stereotypical pattern in wild-type brains (HelfrichFörster, 1995, 1997). In contrast, in adult $p d f^{01}$ mutants, the axonal projections of one to two sLNvs per brain hemisphere displayed an abnormal morphology, as they continued growing toward the posterior optic tract, without ever crossing the midline (Fig. $1 A, B$ ). Strikingly, such phenotype was present in a large proportion $(80 \%)$ of the $p d f>$ GFP; $p d f^{01}$ mutant brains, while rarely appearing in controls (7\% of $p d f>$ GFP brains; Fig. $1 C$ ).

Taking into account the relevance of PDF in a circadian context (Renn et al., 1999b; Peng et al., 2003; Lin et al., 2004; Shafer and Taghert, 2009; Yoshii et al., 2009), this observation prompted us to a more detailed analysis of its potential role during development.

The sLNvs are first detected in the brain of first-instar larvae $4 \mathrm{~h}$ after hatching (Helfrich-Förster, 1997). This cluster persists through metamorphosis, when the axonal projections in the dorsal protocerebrum arborize more profusely. To examine the onset of the misrouting defect found in adult flies, we analyzed the shape of the $p d f>$ RFP; $p d f^{01}$ sLNvs at the late (wandering) third-instar larval stage (1-L3). Surprisingly, no differences were observed when comparing the dorsal projections in control and $p d f>\mathrm{RFP} ; p d f^{01}$ mutants (Fig. 1D), strongly suggesting that this defect appears later in development.

\section{PDF is required in first-instar larvae for correct circuit establishment in the adult}

To address PDF requirement at different stages during circuit establishment, we took advantage of a transgenic line that allows

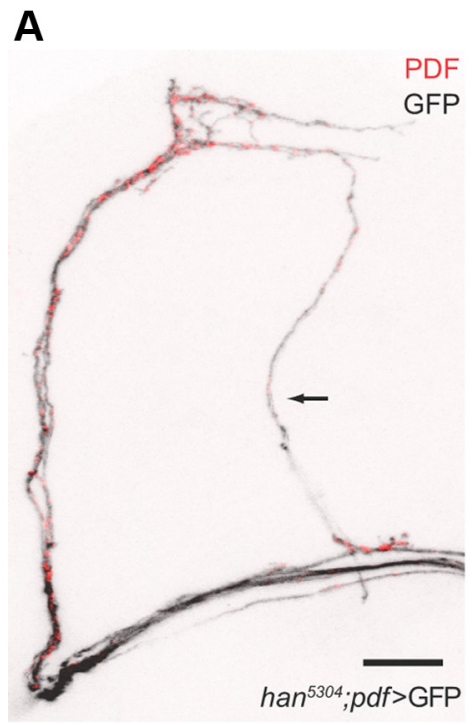

B

\begin{tabular}{|c|c|c|}
\hline Genotype & $\%$ of defect & Significance ${ }^{\phi}$ \\
\hline$p d f>$ GFP & 7.3 & A \\
\hline han ${ }^{5304} ; p d f>$ GFP & 86.0 & $B$ \\
\hline$p d f r>p d f r^{R N A i}$ & 70.0 & B \\
\hline tim $>p d f r^{R N A i}$ & 73.3 & B \\
\hline$p d f>p d f r^{R N A i}$ & 19.3 & $A$ \\
\hline tim.pdf80>pdfr ${ }^{R N A i}$ & 68.7 & B \\
\hline kurs $58>p d f r^{R N A i}$ & 10.7 & $A$ \\
\hline mai301>pdfr RNAi & 17.4 & $A$ \\
\hline ok107>pdfr RNAi & 14.2 & $A$ \\
\hline$c 232>p d f r^{R N A i}$ & 44.4 & C \\
\hline
\end{tabular}

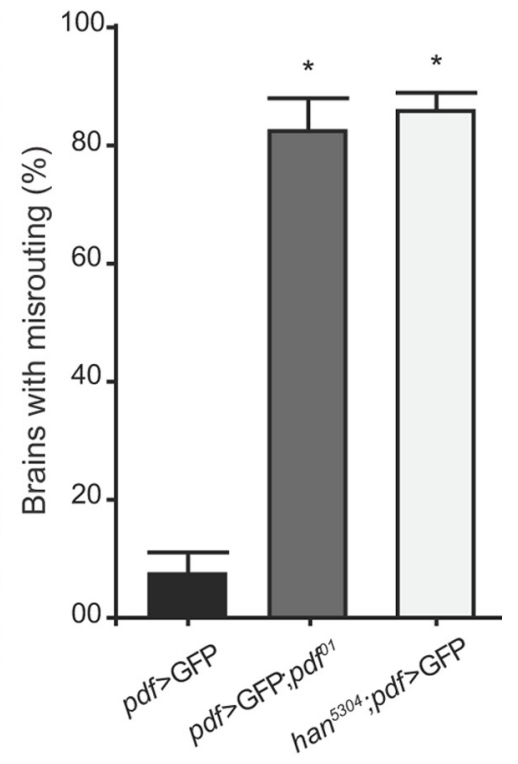

Figure 3. PDFR knockdown in distinct subsets of PDFR + neurons is sufficient to reproduce the misrouting phenotype. $A, B$, PDFR mutant han ${ }^{5304}$ phenocopies $p d f^{01}$ aberrant morphology. $\boldsymbol{A}$, Representative confocal images of the dorsal projections in han ${ }^{5304} ;$ pdf $>$ GFP brains. A subset of the sLNv projections continue their growth toward the POT (marked with an arrow). Brains were stained with anti-GFP (black) and anti-PDF (red) antibodies. Scale bar, $20 \mu \mathrm{m}$. B, Quantification of the misrouting phenotype. The percentage of brains displaying morphological aberrations was significantly different between $p d f>$ GFP and $h a n^{5304}$; $p d f>$ GFP, but no difference was detected between han ${ }^{5304} ; p d f>$ GFP and $p d f>$ GFP/pdf $f^{01}$ (one-way ANOVA, $p<0.001$; Tukey, $p<0.05$; least-significant difference, 27.39\%). Error bars indicate SEM. The asterisk indicates a significant difference between genotypes. C, PDFR downregulation in Tim + PDF - neurons or $\mathrm{C} 232$ + neurons is sufficient to trigger the defect. Different GAL4 lines were employed to downregulate PDFR in specific neuronal clusters. $p d f r>p d f r^{P_{N A i-427246 D}}$ and tim $>$ pdfr ${ }^{\text {PNAi-427246D }}$ reproduce the abnormal phenotype (not significantly different from han ${ }^{5304}$;pdf $>$ GFP). pdf $>$ pdfr ${ }^{\text {RNAi-42724GD }}$ was indistinguishable from $p d f>$ GFP. pdfr silencing in clock neurons excluding the PDF+ cells (tim.pdf80 $>$ pdff ${ }^{\text {PNAi-427246D) }}{ }^{\text {phenocopied }}$ han $^{5304}$ defects. Downregulation of $p d f r$ in the central complex (c232>pdfr $\left.{ }^{R N A i-427246 D}\right)$ partially reproduced the han ${ }^{5304}$ results. On the contrary, when $p d f f^{R N A i}$ was expressed in mushroom bodies $\left(0 k 107>\right.$ pdf $\left.^{R N A i-427246 D}\right)$ or in the pars intercerebralis

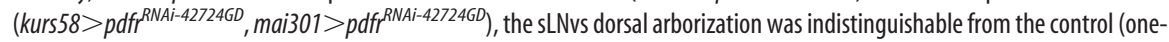
way ANOVA, $p<0.0001$; Duncan, $p<0.05)$. ${ }^{\phi}$ Same letter indicates no significant differences. Three independent experiments were carried out; each experiment included 10 flies per genotype; the mean value is reported.

the expression of an inducible GAL4 version termed GeneSwitch (Osterwalder et al., 2001) only in the PDF circuit, pdf-GS (Depetris-Chauvin et al., 2011). Combining this tool with a $p d f^{R N A i}$ line previously shown to mimic several circadian phenotypes associated to $p d f^{\rho 1}$ (Shafer and Taghert, 2009), we inquired about PDF requirement at distinct developmental stages (Fig. 2A). 
A

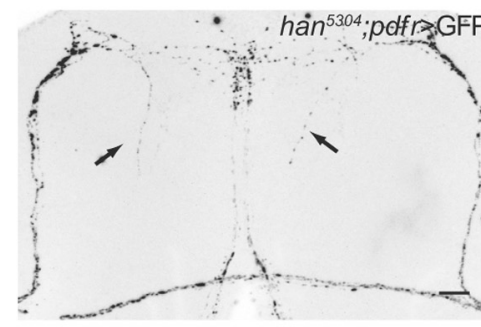

C

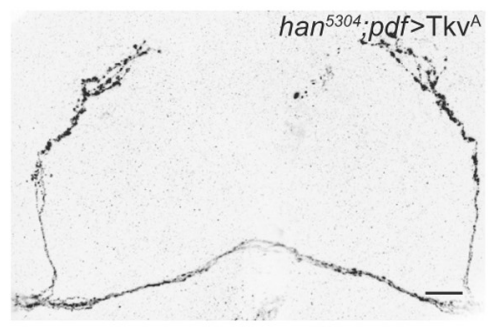

E

\begin{tabular}{|c|c|c|c|c|}
\hline Genotype & $\begin{array}{c}\text { Both sides } \\
\text { affected (\%) }\end{array}$ & Significance & $\begin{array}{c}\text { At least one } \\
\text { side affected (\%) }\end{array}$ & Significance $^{\circ}$ \\
\hline han $^{5304} ;$ pdfr> GFP & 72.0 & A & 87.8 & A \\
han $^{5304} ;$ pdfr $>$ Wg & 70.0 & A & 93.3 & A \\
han $^{5304} ;$ pdfr $>$ GBB & 16.6 & B & 78.7 & A \\
han $^{5304} ; p d f>$ Tkv $^{A}$ & 14.9 & B & 42.4 & B \\
han $^{5304} ; p d f>$ Sax $^{A}$ & 10.8 & B & 38.3 & B \\
\hline
\end{tabular}

Figure 4. Activation of the BMP signaling pathway rescues the $h a n^{5304}$ misrouting phenotype. Ligands from different signaling pathways were expressed in PDFR + cells in the context of a loss-of-function PDFR mutant. $A, B, G B B$ but not Wg partially rescues the $h a n^{5304}$ phenotype. Representative confocal images of projections from whole brains from han $^{5304}$;pdfr $>$ GFP $(\boldsymbol{A})$ and $h a n^{5304}$ pdfr $>$ GBB $(\boldsymbol{B})$. While most han ${ }^{5304}$; pdfr $>$ GFP brains showed defects in both hemispheres, a small proportion of han ${ }^{5304}$; pdfr $>$ GBB brains had defects on both ( $>70$ and $<20 \%$, respectively). Adult brains were dissected and incubated with anti-PDF antiserum to reveal the PDF circuitry. Scale bar, $20 \mu \mathrm{m}$. C, D, Constitutively active forms of Tkv and Sax receptors restore wild-type morphology. Representative confocal images of projections from han ${ }^{5304} ; p d f>\operatorname{Tkv}^{\mathrm{A}}(\boldsymbol{C})$ and $h a n^{5304} ;$ pdf $>\operatorname{Sax}^{\mathrm{A}}(\boldsymbol{D})$ brains. EXpression of either type I receptor (Tkv or Sax) within the PDF circuit significantly reduced the percentage of $p d f$ mutant brains displaying a misrouting defect. $\boldsymbol{E}$, Summary of the results obtained. Statistical analysis included one-way ANOVA ("at least one side affected," $p=0.0006$; "both sides affected," $p<0.0001)$ and Tukey $(p<0.05$ in both cases; "at least one side affected" least significant difference, 33.46\%; "both sides affected" least significant difference, 26.72\%). "Same letter indicates no significant differences. Three independent experiments were carried out. Approximately 10 flies were analyzed per genotype/experiment, and a mean value is reported.

To confirm that downregulation of PDF levels through $p d f$-GS mimicked $p d f^{\rho 1}$ structural phenotypes, flies carrying $p d f^{R N A i}$ ( $p d f$ GS $>p d f^{R N A i}$ ) along with controls ( $p d f-\mathrm{GS}>+$ ) were exposed to RU486 throughout development (Dev+Ad). Chronic downregulation of PDF recreated the aberrant phenotype characteristic of $p d f^{01}$ flies (Fig. 2C), underscoring that loss of PDF function triggers the misrouted morphology.

Subsequently, to identify the temporal window of PDF requirement, acute downregulation of PDF levels was restricted to well characterized stages that cover the entire life cycle: first (L1), second (L2), early-third (e-L3), and late-third (l-L3)-instar larvae, pupa (P), and adulthood (Ad) (Fig. 2A,C). PDF downregulation after adult emergence provided the first indication of its early requirement for the correct establishment of the PDF circuitry (Fig. $2 B$, left panel; $C$ ). Brains acutely lacking PDF as adults were indistinguishable from wild-type controls, supporting the notion that PDF plays an active role in the acquisition of the adult structure. Further analysis of the larval and pupal stages helped us to distinguish the temporal window in which PDF is required. The adult aberrant phenotype was only observed in the group of flies in which PDF was downregulated in L1 (Fig. $2 B$, right panel; $C$ ). Thus, although PDF levels have recovered in the adult brain, the transient PDF downregulation early in development was enough to ensure the misrouting phenotype. None of the other groups showed differences with controls as far as the dorsal projections are considered (Fig. 2C). These observations indicate that PDF plays an active role during circuit establishment very early in development. Remarkably, although PDF seems to be required during $\mathrm{Ll}$, defects are absent in the projections from the sLNvs in the larval brain (1-L3; Fig. 1D), only appearing after the remodeling that takes place during metamorphosis.

Rhythmic locomotor activity is highly sensitive to altered PDF levels (Wülbeck et al., 2008; Shafer and Taghert, 2009). To confirm that they completely recovered after acute downregulation in L1, we monitored locomotor activity in flies in which PDF was downregulated at that early stage, and compared its activity profile with those undergoing acute downregulation during the adult phase (Fig. $2 D)$. As expected, acute downregulation of PDF levels in adult flies recreated $p d f^{01}$ phenotypes [loss of rhythmicity in approximately one-half of the population; period shortening in those that remained rhythmic (Renn et al., 1999b)]. On the contrary, no gross phenotypes were associated with the presence of the structural defect derived from PDF downregulation in L1 (Fig. 2D), as predicted from previous reports showing that a single dorsal projection is sufficient to elicit circadian locomotor rhythmicity in disconnected mutant flies (Helfrich-Förster, 1998).

\section{PDF receptor knockdown in PDF-negative clock neurons} phenocopies the $p d f^{01}$ misrouting defect

PDF signals through a class II G-protein-coupled receptor known as PDFR (Hyun et al., 2005; Lear et al., 2005; Mertens et al., 2005). PDFR mutants like han ${ }^{5304}$ perfectly mimic the behavioral phenotype of $p d f^{01}$ (Hyun et al., 2005; Lear et al., 2005; Mertens et al., 2005). han $^{5304}$ lacks all seven transmembrane domains and the $C$ terminus, and is the best characterized PDFR mutant (Hyun et al., 2005; Shafer et al., 2008). We next wondered whether this novel PDF role was achieved through the same receptor that is relevant for adult behavior. To address this possibility, the $p d f$ $>$ GFP reporter was introduced in the $h a n^{5304}$ mutant background and the morphology of the sLNv projections was evaluated $\left(h a n^{5304} ; p d f>\right.$ GFP). As expected, han ${ }^{5304}$ brains were indistinguishable from $p d \rho^{01}$ ones, with $\sim 86 \%$ of them displaying the same aberration as $p d f^{01}$ (Fig. $3 A, B$ ). 
PDFR has a broad expression pattern in the brain, encompassing both circadian and noncircadian neurons, including some sLNvs (Im and Taghert, 2010). To narrow down the cluster in which PDFR was required, we employed different GAL4 drivers to restrict PDFR downregulation to specific cell groups. Not surprisingly, PDFR downregulation in the $p d f r$ pattern resulted in phenotypes identical with those of $h^{2} n^{5304}$, thus validating the approach (Fig. 3C). Interestingly, PDFR downregulation in TIMpositive (TIM + ) cells was sufficient to recreate the aberrant phenotype. Since PDF+ neurons are also TIM +, we next evaluated a potential cell-autonomous effect using $p d f$-GAL4. PDFR downregulation restricted to PDF+ neurons did not have any effect in the shape of the circuit, hence excluding an autocrine requirement for PDF signaling during circuit establishment (Fig. 3C). To confirm that the PDF neuropeptide was required downstream of the PDF circuit, we combined timGAL4 with $p d f$-GAL80, precluding GAL4 activation in PDF+ cells, so that GAL4 is only active in TIM+PDF- neurons. Again, PDFR downregulation in TIM+PDF- neurons was sufficient to trigger the misrouting defect.

In addition, to test the contribution of noncircadian cells in this phenomenon, $p d f r$ was downregulated through GAL4 expression in specific clusters. Interestingly, downregulation of PDFR signaling limited to the central complex [c232 (Martin et al., 1999)] gave rise to a partial misrouting phenotype ( $\sim 50 \%$ of affected brains), in contrast to the lack of phenotype derived from silencing PDFR in the mushroom bodies [through ok107 (Connolly et al., 1996)] and pars intercerebralis [kurs58, mai 301 (Siegmund and Korge, 2001)]. In sum, PDF signaling through PDFR in postsynaptic clock and nonclock neurons is important for the correct refinement of the projections of certain sLNvs.

\section{The GBB pathway acts as the retrograde signal in sLNv development}

A correct connectivity requires a bidirectional communication between presynaptic and postsynaptic cells. In recent years, a handful of morphogens were identified as the signals implicated in this cross talk, particularly GBB (Aberle et al., 2002; Marqués et al., 2002; McCabe et al., 2003, 2004; Rawson et al., 2003) and Wg (Packard et al., 2002).

To further investigate the mechanisms that shape the projections of the sLNvs, we sought to identify the retrograde signal released by TIM+PDF- neurons, employing GBB and Wg as primary candidates. We hypothesized that overexpression of the retrograde messenger could overcome the lack of PDF signaling in $h a n^{5304}$, consequently restoring the wild-type morphology. To test this possibility, we used $p d f r$ to drive expression of either GBB or $\mathrm{Wg}$ in $h a{ }^{5304}$. While $\mathrm{Wg}$ overexpression did not rescue the $h_{a} n^{5304}$ phenotype, a partial rescue was achieved when GBB was overexpressed (Fig. $4 B, E$ ). In contrast to the pervasive phenotype ( $>70 \%$ of the brains) observed in $h a n^{5304},<20 \%$ displayed aberrant projections on both hemispheres (Fig. 4B,E). Such incomplete rescue could be due either to a failure to achieve the required GBB levels, and/or the possibility that additional BMP ligands could be relevant in this process.

In a complementary approach, constitutively active type I receptors of the BMP pathway were expressed specifically in the PDF circuit. Since GBB can signal through Tkv and Sax (Haerry et al., 1998), both receptors were tested. Interestingly, this strategy proved to be highly efficient to prevent the misrouting phenotype, achieving full rescue with both Tkv and Sax (Fig. 4C-E). Next, we wondered whether the canonical BMP pathway was recruited during sLNvs remodeling. This pathway comprises two
Table 1. The BMP canonical pathway is important for sLNv development

\begin{tabular}{|c|c|c|}
\hline Genotype & $\%$ sLNvs defect & Significance $^{a}$ \\
\hline pdf.Dicer;myrRFP $>+$ & 24.3 & A \\
\hline pdf.Dicer,myrRFP $>$ tkv $v^{\text {RNAi-105834KK }}$ & 58.1 & B \\
\hline pdf.Dicer,myrRFP > wit ${ }^{\text {RNAi-103808KK }}$ & 66.4 & B \\
\hline pdf.Dicer;myrRFP $>$ med $^{\text {RNAi-106767KK }}$ & 74.2 & B \\
\hline pdf.Dicer,myrRFP $>$ mad $^{\text {RNAi-110517KK }}$ & 84.6 & B \\
\hline
\end{tabular}

Downregulation of $t k v$, wit, med, or mad using specific RNAis led to aberrant phenotypes including not only misrouting of specific projections but also the complete absence of the terminal arborizations. Similar defects were observed when RNAi lines from independent collections were used (\% sLNvs defect, pdf.Dicer;myrRFP $>$ tkv ${ }^{\text {RNAi-31040Trip }}=$ $54.55 \%$; pdf.Dicer;myrRFP $>$ wit $^{\text {RAAi-25949Trip }}=80.00 \%$; pdf.Dicer; myrRFP $>$ med $\left.^{\text {RNAi-31928Trip }}=100.00 \%\right)$. Statistical analysis included a one-way ANOVA ( $p=0.0011$ ) with Tukey's post hoc test $(p<0.05$; least significant difference, $32.1 \%$ )

${ }^{a}$ Same letter indicates no significant differences. Three independent experiments were examined; each experiment included 10 flies per genotype; the mean value is reported.

Table 2. GBB expression by PDFR + neurons is required for proper $\mathrm{LLNvs}$ development

\begin{tabular}{|c|c|c|}
\hline Genotype & $\%$ sLNvs defect & Significance $^{a}$ \\
\hline pdfr.Dicer $>+$ & 10.0 & A \\
\hline$p d f r$ Dicer $>g b b^{\text {RNAi-Wharton }}$ & 81.7 & B \\
\hline$p d f r . D i c e r>d p p^{R N A i-33767 T r i p}$ & 34.4 & A \\
\hline pdfr.Dicer $>$ myo ${ }^{\text {RNAi-31114Trip }}$ & 30.0 & A \\
\hline pdfr.Dicer $>$ mav $^{\text {RNAi-34650Trip }}$ & 16.7 & A \\
\hline pdfr.Dicer $>a c^{\text {RNAi-29597Trip }}$ & 17.8 & A \\
\hline
\end{tabular}

$g b b$ downregulation in PDFR + neurons led to morphological defects in the arborization of the sLNv terminals. Silencing $g b b$ triggered not only misrouting of specific projections but also shortening or, in extreme examples, the complete absence of the terminal arborizations, similarly to what was observed upon downregulation of BMP pathway components. Downregulation of $d p p$ and myo affected a smaller proportion of adult brains. Although act silencing did not result in misrouting phenotypes, this RNAi line is able to effectively downregulate act levels (A. Pérez-Santángelo and M. F. Ceriani, unpublished data). Statistical analysis included a one-way ANOVA ( $p=0.0004)$ with Tukey's post hoc test ( $p<0.05$; least-significant difference, $39.9 \%$ ).

${ }^{a}$ Same letter indicates no significant differences. Three independent experiments were examined; each experiment included 10 flies per genotype; the mean value is reported.

possible type I receptors (Tkv and Sax) that become active when a type II receptor (Wit, a constitutively active kinase) phosphorylates them, upon ligand binding. Either Sax or Tkv phosphorylates Mad, which in turn binds to Med and translocates into the nucleus (Marqués, 2005). To test our hypothesis, specific RNAis were expressed within the PDF circuit. Noteworthy, restricted downregulation (i.e., in the PDF circuit) of Tkv, Wit, Mad, or Med recreated the sLNv aberrant phenotype. On occasion, downregulation of either one of these molecules affected the projections of all four sLNvs. In extreme examples, the sLNv projections reached the dorsal part of the brain but lacked any arborization to the dorsal protocerebrum (Table 1). This finding strongly suggests that the BMP signaling pathway is active in all four sLNvs at times of circuit refinement, but some of them appear to depend on a different ligand combination.

The TGF- $\beta$ ligand family has seven members in Drosophila, decapentaplegic [dpp (Panganiban et al., 1990)], screw [scw (Neul and Ferguson, 1998)], gbb (Khalsa et al., 1998), maverick [mav (Nguyen et al., 2000)], myoglianin [myo (Lo and Frasch, 1999)], activin [act (Kutty et al., 1998)], and dawdle [daw (Parker et al., 2006)]. Some of them, such as myo, have been implicated in circuit refinement in the mushroom bodies (Awasaki et al., 2011). To identify additional TGF- $\beta$ ligands involved in sLNv development, specific RNAi lines targeting act, mav, myo, $d p p$, and $g b b$ were expressed in PDFR + neurons. Only g $b b$ downregulation in PDFR+ neurons triggered a structural defect (Table 2). However, when $d p p$ or myo was downregulated, $\sim 30 \%$ of the brains displayed aberrant phenotypes, although this proportion was not significantly different from the control. It is worth mentioning that, as reported for other member of the signaling path- 
A

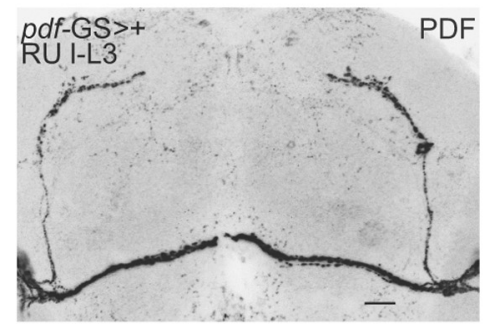

C

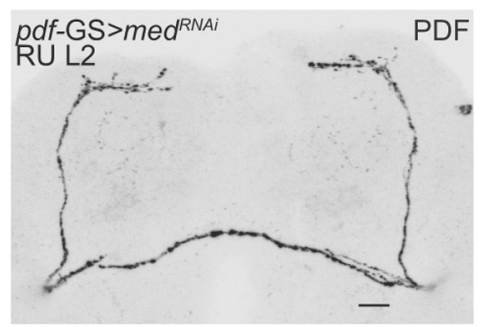

E

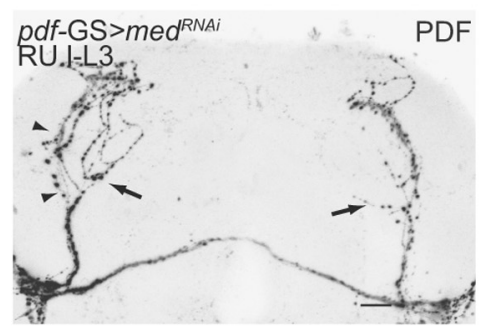

G

\begin{tabular}{|c|c|c|c|}
\hline Stage & Genotype & $\%$ of defect & p-value \\
\hline L1 & $\begin{array}{c}p d f-G S>+ \\
p d f-G S>m e d^{R N A i}\end{array}$ & $\begin{array}{l}14.1 \\
6.7\end{array}$ & 0.551 \\
\hline L2 & $\begin{array}{c}p d f-G S>+ \\
p d f-G S>m e d^{R N A i}\end{array}$ & $\begin{array}{l}23.3 \\
20.7\end{array}$ & 0.864 \\
\hline early-L3 & $\begin{array}{c}p d f-G S>+ \\
p d f-G S>m e d^{R N A i}\end{array}$ & $\begin{array}{l}17.9 \\
58.9\end{array}$ & 0.002 \\
\hline late-L3 & $\begin{array}{c}p d f-G S>+ \\
p d f-G S>m e d^{R N A i}\end{array}$ & $\begin{array}{l}17.8 \\
76.3\end{array}$ & $<0.001$ \\
\hline Pupa & $\begin{array}{c}p d f-G S>+ \\
p d f-G S>m e d^{R N A i}\end{array}$ & $\begin{array}{l}38.5 \\
92.6\end{array}$ & $<0.001$ \\
\hline
\end{tabular}

Figure 5. Med is required from $L 3$ to pupa for proper development of the $L$ LNvs. med was downregulated using a specific RNAi. A similar protocol to that in Figure $2 A$ was employed (Dev $+\mathrm{Ad}$ and Ad were not evaluated). $\boldsymbol{A}-\boldsymbol{F}$, Representative confocal images of projections from whole adult brains from $p d f-G S>+$ and $p d f-G S>m^{\text {RNAi-106767KK }}$ flies soaked in RU at different developmental stages. Only those in which med was downregulated in e-L3, I-L3, or pupa resulted in abnormal projections in the adulthood. Brains were stained with anti-PDF antibody (black). $\boldsymbol{A}$, Control pdf-GS $>+$. RU was administrated at I-L3. B-F,pdf-GS $>$ med $^{\text {RNAi-106767KK }}$. RU was administrated at $\mathrm{L} 1(\boldsymbol{B}), \mathrm{L} 2(\boldsymbol{C}), \mathrm{e}-\mathrm{L} 3(\boldsymbol{D}), \mathrm{I}-\mathrm{L} 3(\boldsymbol{E})$, and pupa $(\boldsymbol{F})$. G, Summary of the result obtained. Statistical analysis included a two-way ANOVA. The interaction was significant $(p=0.0009)$. Only treatments involving downregulation in e- $\mathrm{L} 3, \mathrm{I}-\mathrm{L} 3$, and pupa produced an aberrant morphology. Defects included misrouting (arrows) and defasciculation (arrowheads). As seen in $\boldsymbol{F}$, in some cases projections from the large ventral lateral neurons were also affected. Experiments were repeated three times independently; $\sim 10$ brains were analyzed per genotype/experiment; the mean value is reported.

way (Table 1), on occasion gbb downregulation causes stronger phenotypes (i.e., loss or shortening of the axonal arborizations).

In sum, these results show that the synaptic refinement of the PDF circuitry requires GBB acting through its canonical pathway.
Activation of the GBB pathway is required from third-instar larva to pupa

Since PDF is required in L1 (Fig. 2), but the structural defects become apparent only in the adult (Fig. 1D, bottom panel), we attempted to define the temporal window of pathway activation through stagespecific downregulation of med levels (similarly to the experiment presented in Fig. 2).

Acute med downregulation in L1 and L2 did not trigger any phenotypes on sLNvs morphology, which was indistinguishable from controls (Fig. 5A-C). Instead, when med was downregulated during e-L3, 1-L3, or pupa, adult sLNvs exhibited misrouting and defasciculation defects, reminiscent of those observed after longer term downregulation (Table 1). As described, med downregulation affected all four sLNvs. The severity of the aberrations could be accounted for a potential Med activity on different target genes.

This observation confirmed the temporal separation between the release of the PDF signal, which could act through "tagging" of postsynaptic neurons, and the reception of the GBB signal acting on the sLNvs. Interestingly, the fact that med downregulation triggers structural defects in several stages suggests that this pathway plays a role in various steps relevant to the acquisition of the mature shape.

\section{Discussion}

In this study, we show a developmental role for PDF and identified the pathway operating in a subset of sLNvs during target recognition. PDF released from the dorsal sLNv projections during early stages in larval development is sensed in TIM+PDF - neurons through PDFR. This likely triggers an unknown gene program ("tag") that later on results in the expression and release of GBB at the end of the larval stage or early metamorphosis. Thus, GBB acts as a retrograde signal during the refinement of the axonal arborization of a subset of sLNvs. In turn, upon GBB binding to Wit and Tkv (or Sax), the canonical pathway is activated in PDF+ cells and, in a Mad-dependent fashion, dictates the correct refinement of the PDF circuit connectivity.

\section{Role of the BMP pathway in the establishment of adult brain connectivity}

The members of the TGF $\beta$ superfamily play multiple roles during development, acting as morphogens to determine embryonic patterning (Ferguson and Anderson, 1992), regulating cell proliferation in the larval brain (Zhu et al., 2008), larval NMJ growth 
(McCabe et al., 2003), or the remodeling of larval olfactory projection neurons and $\gamma$-neurons in the mushroom bodies through metamorphosis (Marin et al., 2005; Yoshida et al., 2005). Specific TGF $\beta$ ligands such as Myoglianin and type I receptor Baboon are necessary for the latter (Awasaki et al., 2011). Here, we show that the TGF $\beta$ pathway is also involved in the refinement of sLNv dorsal projections, although it requires GBB, a different subfamily ligand, and its dedicated receptors. Our analysis showed that Wit, Tkv, and Sax are the receptors employed by the sLNvs to sense this retrograde signal and activate the canonical pathway. In addition, and in contrast to what has recently been reported for the $\gamma$-neurons where the source of the retrograde signal comes from astrocyte-like glial cells in the larval cortex (Awasaki et al., 2011), we demonstrated that GBB release from PDFR+ neurons is able to rescue $h a n^{5304}$.

\section{A novel role for PDF}

Despite the absence of a misrouting phenotype during larval stages, PDF is required during first-instar larva. Downregulation of $p d f$ levels at any other time does not give rise to an aberrant morphology in adult projections. Although the exact timing of each event remains elusive, PDF action in L1 affects a remodeling process that occurs faraway in time. One possibility to account for this observation is that the PDFR pathway activates a specific transcriptional program in PDFR+ circadian and/or locomotor neurons (i.e., "tags" them), which results in delayed expression of GBB during the remodeling process. In time, activation of the GBB signaling pathway in the sLNvs could trigger an increased expression of the B1 type ecdysone receptor (EcR) (Awasaki et al., 2011), known to have a substantial ligandindependent activity (Brown and Truman, 2009), thus switching on a variety of target genes involved in the remodeling process. In support of this possibility, silencing the ecdysone receptor in $\mathrm{PDF}+$ cells phenocopies the acute downregulation of mad or med (Fig. 6), providing an additional key player in the mechanism of PDF-mediated circuit refinement.

To account for this temporal separation, we propose that early on PDFR activation is required in neural progenitors of future PDF targets to switch on a gene program allowing GBB expression at the end of the larval stage. Thus, GBB could be playing a dual role during circuit development; when the process begins during third-instar larvae it could be the signal that triggers EcR expression, while later on during metamorphosis it could be the cue followed by certain sLNvs to direct their growth toward their targets.

Suppression of PDF expression in the sLNvs or pdfr downregulation in $\mathrm{TIM}+\mathrm{PDF}-$ and $\mathrm{C} 232+$ neurons triggers a misrouting defect on the projections of certain sLNvs. Surprisingly, although the PDF circuitry is established very early during larval development and-as shown in this study-requires PDF in L1 to achieve proper adult morphology, the misrouting phenotype is absent in $p d f^{01}$ by the end of the larval stage, underscoring that this communication is still functional during
C

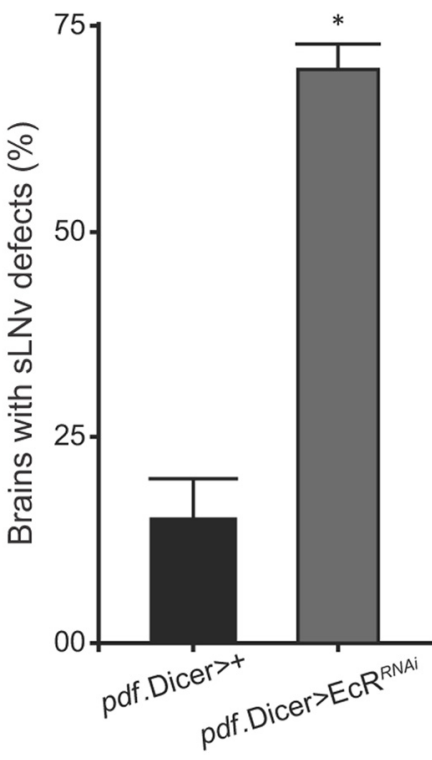

Figure 6. The ecdysone receptor is implicated in SLNv development. A specific RNAi directed toward the EcR was expressed xpressing $E C R^{R N A i-37059 G D}$ and controls (one-way ANOVA, $p=0.011$ ). Two independent experiments were carried out. Approximately 10 flies were analyzed per genotype/experiment, and a mean value is reported. Error bars indicate SEM. The asterisk indicates a significant difference between genotypes.

metamorphosis, a period of active circuit remodeling. During early metamorphosis, neurons forming larval circuits first prune and then reextend their projections to shape the adult-specific circuits (Lee et al., 1999; Watts et al., 2003; Awasaki and Ito, 2004). Our results suggest that the sLNv projections probably degenerate during early metamorphosis, and later reextend in search for new targets. Supporting this idea, the larval circadian network is fairly simple (Helfrich-Förster, 1995; Kaneko et al., 1997), composed of five lateral neurons, four of which express PDF, and four dorsal neurons. All the remaining clusters, some of which are PDF targets (Shafer et al., 2008; Yao et al., 2012), become detectable during metamorphosis (Helfrich-Förster et al., 2007). Similarly, the first structure identifiable as a primordium of the central complex appears during late larval stages, and includes neurons belonging to several secondary lineages produced at that time (Renn et al., 1999a; Young and Armstrong, 2010; Pereanu et al., 2011). Thus, we propose that reextension of the sLNv projections searching for novel targets requires GBB (and potentially DPP and MYO) as a retrograde signal.

PDF does not appear to be the only signal released early on by the sLNvs since acute downregulation of BMP pathway components led to more dramatic structural phenotypes, underscoring that additional ligands and receptors might play a role in shaping the adult architecture of the circuit. The fact that an endogenous signal is relevant in defining the architecture of an adult circuit is not unprecedented. Indeed, it has long been demonstrated that 5-HT fibers depend on 5-HT for normal circuit arborizations (Budnik et al., 1989).

\section{Differences between the sLNvs}

No differences between the four PDF expressing sLNvs have been identified (Johard et al., 2009). Remarkably, we report that some 
sLNvs are more sensitive than others to the absence of PDF during development, providing an indication that such difference exists. However, downregulation of specific BMP pathway components affects all of them to a different degree. Taking this together, we conclude that different sLNvs could be using different anterograde and retrograde signals to acquire their adult configuration. It is tempting to speculate that certain sLNvs release molecules other than PDF, which in turn could be sensed by PDFR - postsynaptic cells.

The simplicity of the PDF circuit coupled to the presence of all canonical pathway components makes this a unique setting to further establish the rules underlying the complexity of BMP signaling.

\section{References}

Aberle H, Haghighi AP, Fetter RD, McCabe BD, Magalhães TR, Goodman CS (2002) wishful thinking encodes a BMP type II receptor that regulates synaptic growth in Drosophila. Neuron 33:545-558. CrossRef Medline

Atwood HL, Govind CK, Wu CF (1993) Differential ultrastructure of synaptic terminals on ventral longitudinal abdominal muscles in Drosophila larvae. J Neurobiol 24:1008-1024. CrossRef Medline

Awasaki T, Ito K (2004) Engulfing action of glial cells is required for programmed axon pruning during Drosophila metamorphosis. Curr Biol 14:668-677. CrossRef Medline

Awasaki T, Huang Y, O'Connor MB, Lee T (2011) Glia instruct developmental neuronal remodeling through TGF- $\beta$ signaling. Nat Neurosci 14: 821-823. CrossRef Medline

Brown HL, Truman JW (2009) Fine-tuning of secondary arbor development: the effects of the ecdysone receptor on the adult neuronal lineages of the Drosophila thoracic CNS. Development 136:3247-3256. CrossRef Medline

Budnik V, Wu CF, White K (1989) Altered branching of serotonincontaining neurons in Drosophila mutants unable to synthesize serotonin and dopamine. J Neurosci 9:2866-2877. Medline

Ceriani MF, Hogenesch JB, Yanovsky M, Panda S, Straume M, Kay SA (2002) Genome-wide expression analysis in Drosophila reveals genes controlling circadian behavior. J Neurosci 22:9305-9319. Medline

Connolly JB, Roberts IJ, Armstrong JD, Kaiser K, Forte M, Tully T, O’Kane CJ (1996) Associative learning disrupted by impaired Gs signaling in Drosophila mushroom bodies. Science 274:2104-2107. CrossRef Medline

Depetris-Chauvin A, Berni J, Aranovich EJ, Muraro NI, Beckwith EJ, Ceriani MF (2011) Adult-specific electrical silencing of pacemaker neurons uncouples molecular clock from circadian outputs. Curr Biol 21:1783-1793. CrossRef Medline

Ferguson EL, Anderson KV (1992) Decapentaplegic acts as a morphogen to organize dorsal-ventral pattern in the Drosophila embryo. Cell 71: 451-461. CrossRef Medline

Grima B, Chélot E, Xia R, Rouyer F (2004) Morning and evening peaks of activity rely on different clock neurons of the Drosophila brain. Nature 431:869-873. CrossRef Medline

Haerry TE, Khalsa O, O'Connor MB, Wharton KA (1998) Synergistic signaling by two BMP ligands through the SAX and TKV receptors controls wing growth and patterning in Drosophila. Development 125:3977-3987. Medline

Helfrich-Förster C (1995) The period clock gene is expressed in central nervous system neurons which also produce a neuropeptide that reveals the projections of circadian pacemaker cells within the brain of Drosophila melanogaster. Proc Natl Acad Sci U S A 92:612-616. CrossRef Medline

Helfrich-Förster C (1997) Development of pigment-dispersing hormoneimmunoreactive neurons in the nervous system of Drosophila melanogaster. J Comp Neurol 380:335-354. CrossRef Medline

Helfrich-Förster C (1998) Robust circadian rhythmicity of Drosophila melanogaster requires the presence of lateral neurons: a brain-behavioral study of disconnected mutants. J Comp Physiol A 182:435-453. CrossRef Medline

Helfrich-Förster C (2003) The neuroarchitecture of the circadian clock in the brain of Drosophila melanogaster. Microsc Res Tech 62:94-102. CrossRef Medline

Helfrich-Förster C, Shafer OT, Wülbeck C, Grieshaber E, Rieger D, Taghert P (2007) Development and morphology of the clock-gene-expressing lat- eral neurons of Drosophila melanogaster. J Comp Neurol 500:47-70. CrossRef Medline

Hyun S, Lee Y, Hong ST, Bang S, Paik D, Kang J, Shin J, Lee J, Jeon K, Hwang S, Bae E, Kim J (2005) Drosophila GPCR Han is a receptor for the circadian clock neuropeptide PDF. Neuron 48:267-278. CrossRef Medline

Im SH, Taghert PH (2010) PDF receptor expression reveals direct interactions between circadian oscillators in Drosophila. J Comp Neurol 518: 1925-1945. CrossRef Medline

Im SH, Li W, Taghert PH (2011) PDFR and CRY signaling converge in a subset of clock neurons to modulate the amplitude and phase of circadian behavior in Drosophila. PLoS One 6:e18974. CrossRef Medline

Johard HA, Yoishii T, Dircksen H, Cusumano P, Rouyer F, Helfrich-Förster C, Nässel DR (2009) Peptidergic clock neurons in Drosophila: ion transport peptide and short neuropeptide $\mathrm{F}$ in subsets of dorsal and ventral lateral neurons. J Comp Neurol 516:59-73. CrossRef Medline

Kaneko M, Helfrich-Förster C, Hall JC (1997) Spatial and temporal expression of the period and timeless genes in the developing nervous system of Drosophila: newly identified pacemaker candidates and novel features of clock gene product cycling. J Neurosci 17:6745-6760. Medline

Khalsa O, Yoon JW, Torres-Schumann S, Wharton KA (1998) TGF-beta/ BMP superfamily members, Gbb-60A and Dpp, cooperate to provide pattern information and establish cell identity in the Drosophila wing. Development 125:2723-2734. Medline

Kutty G, Kutty RK, Samuel W, Duncan T, Jaworski C, Wiggert B (1998) Identification of a new member of transforming growth factor-beta superfamily in Drosophila: the first invertebrate activin gene. Biochem Biophys Res Commun 246:644-649. CrossRef Medline

Lear BC, Merrill CE, Lin JM, Schroeder A, Zhang L, Allada R (2005) A G protein-coupled receptor, groom-of-PDF, is required for PDF neuron action in circadian behavior. Neuron 48:221-227. CrossRef Medline

Lear BC, Zhang L, Allada R (2009) The neuropeptide PDF acts directly on evening pacemaker neurons to regulate multiple features of circadian behavior. PLoS Biol 7:e1000154. CrossRef Medline

Lee T, Lee A, Luo L (1999) Development of the Drosophila mushroom bodies: sequential generation of three distinct types of neurons from a neuroblast. Development 126:4065-4076. Medline

Lin Y, Stormo GD, Taghert PH (2004) The neuropeptide pigmentdispersing factor coordinates pacemaker interactions in the Drosophila circadian system. J Neurosci 24:7951-7957. CrossRef Medline

Lo PC, Frasch M (1999) Sequence and expression of myoglianin, a novel Drosophila gene of the TGF- $\beta$ superfamily. Mech Dev 86:171-175. CrossRef Medline

Marin EC, Watts RJ, Tanaka NK, Ito K, Luo L (2005) Developmentally programmed remodeling of the Drosophila olfactory circuit. Development 132:725-737. CrossRef Medline

Marqués G (2005) Morphogens and synaptogenesis in Drosophila. J Neurobiol 64:417-434. CrossRef Medline

Marqués G, Bao H, Haerry TE, Shimell MJ, Duchek P, Zhang B, O'Connor MB (2002) The Drosophila BMP type II receptor Wishful Thinking regulates neuromuscular synapse morphology and function. Neuron 33: 529-543. CrossRef Medline

Martin JR, Raabe T, Heisenberg M (1999) Central complex substructures are required for the maintenance of locomotor activity in Drosophila melanogaster. J Comp Physiol A 185:277-288. Medline

McCabe BD, Marqués G, Haghighi AP, Fetter RD, Crotty ML, Haerry TE, Goodman CS, O'Connor MB (2003) The BMP homolog Gbb provides a retrograde signal that regulates synaptic growth at the Drosophila neuromuscular junction. Neuron 39:241-254. CrossRef Medline

McCabe BD, Hom S, Aberle H, Fetter RD, Marqués G, Haerry TE, Wan H, O'Connor MB, Goodman CS, Haghighi AP (2004) Highwire regulates presynaptic BMP signaling essential for synaptic growth. Neuron 41:891905. CrossRef Medline

Mertens I, Vandingenen A, Johnson EC, Shafer OT, Li W, Trigg JS, De Loof A, Schoofs L, Taghert PH (2005) PDF receptor signaling in Drosophila contributes to both circadian and geotactic behaviors. Neuron 48:213-219. CrossRef Medline

Nellen D, Burke R, Struhl G, Basler K (1996) Direct and long-range action of a DPP morphogen gradient. Cell 85:357-368. CrossRef Medline

Neul JL, Ferguson EL (1998) Spatially restricted activation of the SAX receptor by SCW modulates DPP/TKV signaling in Drosophila dorsal-ventral patterning. Cell 95:483-494. CrossRef Medline

Nguyen M, Parker L, Arora K (2000) Identification of maverick, a novel 
member of the TGF-beta superfamily in Drosophila. Mech Dev 95:201206. CrossRef Medline

Osterwalder T, Yoon KS, White BH, Keshishian H (2001) A conditional tissue-specific transgene expression system using inducible GAL4. Proc Natl Acad Sci U S A 98:12596-12601. CrossRef Medline

Packard M, Koo ES, Gorczyca M, Sharpe J, Cumberledge S, Budnik V (2002) The Drosophila Wnt, wingless, provides an essential signal for pre- and postsynaptic differentiation. Cell 111:319-330. CrossRef Medline

Panganiban GE, Rashka KE, Neitzel MD, Hoffmann FM (1990) Biochemical characterization of the Drosophila dpp protein, a member of the transforming growth factor beta family of growth factors. Mol Cell Biol 10: 2669-2677. Medline

Parisky KM, Agosto J, Pulver SR, Shang Y, Kuklin E, Hodge JJ, Kang K, Liu X, Garrity PA, Rosbash M, Griffith LC (2008) PDF cells are a GABAresponsive wake-promoting component of the Drosophila sleep circuit. Neuron 60:672-682. CrossRef Medline

Parker L, Ellis JE, Nguyen MQ, Arora K (2006) The divergent TGF-beta ligand Dawdle utilizes an activin pathway to influence axon guidance in Drosophila. Development 133:4981-4991. CrossRef Medline

Peng Y, Stoleru D, Levine JD, Hall JC, Rosbash M (2003) Drosophila freerunning rhythms require intercellular communication. PLoS Biol 1:E13. Medline

Pereanu W, Younossi-Hartenstein A, Lovick J, Spindler S, Hartenstein V (2011) Lineage-based analysis of the development of the central complex of the Drosophila brain. J Comp Neurol 519:661-689. CrossRef Medline

Rawson JM, Lee M, Kennedy EL, Selleck SB (2003) Drosophila neuromuscular synapse assembly and function require the TGF-beta type I receptor saxophone and the transcription factor Mad. J Neurobiol 55:134-150. CrossRef Medline

Renn SC, Armstrong JD, Yang M, Wang Z, An X, Kaiser K, Taghert PH (1999a) Genetic analysis of the Drosophila ellipsoid body neuropil: organization and development of the central complex. J Neurobiol 41:189207. CrossRef Medline

Renn SC, Park JH, Rosbash M, Hall JC, Taghert PH (1999b) A pdf neuropeptide gene mutation and ablation of PDF neurons each cause severe abnormalities of behavioral circadian rhythms in Drosophila. Cell 99:791802. CrossRef Medline

Shafer OT, Taghert PH (2009) RNA-interference knockdown of Drosophila pigment dispersing factor in neuronal subsets: the anatomical basis of a neuropeptide's circadian functions. PLoS One 4:e8298. CrossRef Medline

Shafer OT, Helfrich-Förster C, Renn SC, Taghert PH (2006) Reevaluation of Drosophila melanogaster's neuronal circadian pacemakers reveals new neuronal classes. J Comp Neurol 498:180-193. CrossRef Medline

Shafer OT, Kim DJ, Dunbar-Yaffe R, Nikolaev VO, Lohse MJ, Taghert PH
(2008) Widespread receptivity to neuropeptide PDF throughout the neuronal circadian clock network of Drosophila revealed by real-time cyclic AMP imaging. Neuron 58:223-237. CrossRef Medline

Siegmund T, Korge G (2001) Innervation of the ring gland of Drosophila melanogaster. J Comp Neurol 431:481-491. CrossRef Medline

Stewart BA, Schuster CM, Goodman CS, Atwood HL (1996) Homeostasis of synaptic transmission in Drosophila with genetically altered nerve terminal morphology. J Neurosci 16:3877-3886. Medline

Stoleru D, Peng Y, Agosto J, Rosbash M (2004) Coupled oscillators control morning and evening locomotor behaviour of Drosophila. Nature 431: 862-868. CrossRef Medline

Stoleru D, Peng Y, Nawathean P, Rosbash M (2005) A resetting signal between Drosophila pacemakers synchronizes morning and evening activity. Nature 438:238-242. CrossRef Medline

Watts RJ, Hoopfer ED, Luo L (2003) Axon pruning during Drosophila metamorphosis: evidence for local degeneration and requirement of the ubiquitin-proteasome system. Neuron 38:871-885. CrossRef Medline

Wülbeck C, Grieshaber E, Helfrich-Förster C (2008) Pigment-dispersing factor (PDF) has different effects on Drosophila's circadian clocks in the accessory medulla and in the dorsal brain. J Biol Rhythms 23:409-424. CrossRef Medline

Yao Z, Macara AM, Lelito KR, Minosyan TY, Shafer OT (2012) Analysis of functional neuronal connectivity in the Drosophila brain. J Neurophysiol 108:684-696. CrossRef Medline

Yoshida S, Soustelle L, Giangrande A, Umetsu D, Murakami S, Yasugi T, Awasaki T, Ito K, Sato M, Tabata T (2005) DPP signaling controls development of the lamina glia required for retinal axon targeting in the visual system of Drosophila. Development 132:4587-4598. CrossRef Medline

Yoshii T, Wülbeck C, Sehadova H, Veleri S, Bichler D, Stanewsky R, HelfrichFörster C (2009) The neuropeptide pigment-dispersing factor adjusts period and phase of Drosophila's clock. J Neurosci 29:2597-2610. CrossRef Medline

Young JM, Armstrong JD (2010) Building the central complex in Drosophila: the generation and development of distinct neural subsets. J Comp Neurol 518:1525-1541. CrossRef Medline

Zhu CC, Boone JQ, Jensen PA, Hanna S, Podemski L, Locke J, Doe CQ, O'Connor MB (2008) Drosophila Activin- and the Activin-like product Dawdle function redundantly to regulate proliferation in the larval brain. Development 135:513-521. CrossRef Medline

Zito K, Parnas D, Fetter RD, Isacoff EY, Goodman CS (1999) Watching a synapse grow: noninvasive confocal imaging of synaptic growth in Drosophila. Neuron 22:719-729. CrossRef Medline 